\title{
A escola como expressão da violência ou locus da cultura da paz?
}

The school as an expression of the violence or space of the culture of peace?

Michelle Popenga Geraim Monteiro

Doutoranda em Educação - Universidade Federal do Paraná - Paraná, PR, Brasil mizinhadobru@yahoo.com.br

Tatiane Delurdes de Lima

Doutoranda em Educação - Universidade Federal do Paraná - Paraná, PR, Brasil tati8lima@gmail.com

Araci Asinelli-Luz

Doutora em Educação - Universidade Federal do Paraná - Paraná, PR, Brasil araciasinelli@hotmail.com

Resumo: O objetivo do presente estudo é identificar a escola como microssistema de convivência e transformação, visto que a mesma tem sido considerada como espaço de expressão e manifestação da violência. É resultado de um estudo qualitativo e tem como metodologia o estudo bibliográfico, decorrentes de pesquisas de abordagem teórica, relacionadas ao Mestrado em Educação da Universidade Federal do Paraná. No contexto social e educacional, em defesa de uma escola com base humanizadora, ampliamos o olhar para o âmbito da violência escolar, fazendo uma releitura à luz da Teoria Bioecológica do Desenvolvimento Humano (BRONFENBRENNER, 2011) e a educação transformadora de Paulo Freire (1987; 1996; 2000), aliadas à Cultura da Paz como forma de compreensão e prevenção do fenômeno das violências. Acreditamos que ao compreendermos a escola como espaço de interações aumentamos a chance concreta de uma realidade educativa melhor e de prevenção das violências

Palavras-chave: Adolescência. Educação. Infância. Pedagogia Social. Prevenção.

Abstract: The objective of the present study is to identify the school as a microsystem of coexistence and transformation, since it has been considered as a space for expression and manifestation of violence. It is the result of a qualitative study and has as methodology the bibliographic study, resulting from researches of theoretical approach, related to the Masters in Education of the Federal University of Paraná. In the social and educational context, in defense of a school with a humanizing basis, we broadened our eyes to the scope of school violence, re-reading in the light of the Bioecological Theory of Human Development (BRONFENBRENNER, 2011) and Paulo Freire's , 1996, 2000), allied to the Culture of Peace as a way of understanding and preventing the phenomenon of violence. We believe that by understanding school as a space for interactions we increase the concrete chance for a better educational reality and violence prevention

Keywords: Adolescence; Education. Childhood. Social Pedagogy. Prevention. 


\section{Introdução}

Considerando a família e a escola como microssistemas (espaços ecológicos) estruturantes das manifestações da socialização de crianças e adolescentes e que, em interrelação, constituem o mesossistema essencial para o desenvolvimento humano, conforme o modelo Bioecológico (BRONFENBRENNER, 2011), ressaltamos a importância de sua harmonia e equilíbrio. Para o ambiente escolar, visto que é nele que ocorrem os momentos de maior intensidade de convívio entre pares, experiências coletivas, formação de identidade pessoal e aprendizado cognitivo e de habilidades pró-sociais, o cuidado com a organização dos espaços caracteriza-se como fator de prevenção das violências. Entretanto, pesquisas sobre a escola e sua relação com as violências ganham corpo (MONTEIRO, 2017b; LEMOS, GALINDO, 2012; ROCHA, 2010; STIVAL, 2008; ABRAMOVAY, LIMA, VARELLA, 2003; CHARLOT, 2002), porque há um aumento significativo do fenômeno das violências no campo educacional, por meio de agressões físicas, verbais e psicológicas, frequentes no cotidiano estudantil. Buscando respostas para a compreensão deste fenômeno, consideramos as discussões realizadas por Charlot (2002), ao propor a violência escolar em três modalidades: violência na escola, à escola e da escola. A violência na escola é aquela em que a agressão acontece dentro do espaço escolar, pois ali se encontram sujeitos passíveis disso, seres humanos em sua incompletude. A violência à escola é aquela direcionada a instituição em si, visando a destruição do patrimônio público ou até mesmo de seus agentes, como estudantes, funcionários(as) e professores(as). A violência da escola é caracterizada pelo ato simbólico, cuja ocorrência se dá por meio do tratamento que a instituição, por meio de seus agentes, concebem seus estudantes (currículos inadequados, negação de conhecimentos fundamentais, relações interpessoais autoritárias, estrutura física inadequada e deficitária), bem como a gestão valoriza os(as)profissionais da educação e faz investimentos na área. Portanto, partindo destes pressupostos, é possível inferir que a escola é um local que produz/reproduz/oportuniza as violências, seja por meio de seus atos, pela sua omissão ou até mesmo pela possível fragilidade/vulnerabilidade de seu papel social.

As consequências geradas pelas violências são muitas e afetam toda a sociedade, direta ou indiretamente. Sendo assim, considerada como um fenômeno relacional e sistêmico, uma vez que as proporções das violências são evidenciadas por meio de atitudes individuais e coletivas, a partir de um contexto que favorece sua disseminação. Neste sentido, como contraponto às suas manifestações, buscando compreendê-la de modo mais 
abrangente, com vistas à prevenção, a teoria Bioecológica do Desenvolvimento Humano (2011) permite presumir que as violências se manifestam por meio das interações dinâmicas entre os indivíduos em seus múltiplos ambientes de contato. Por isso, um ambiente/clima escolar hostil e desarmônico afeta, não somente a aprendizagem cognitiva, mas também o desenvolvimento humano integral, físico, emocional e mental de seus estudantes, instalando sentimentos de medo, angústia e insegurança. Outra referência teórica que auxilia na compreensão do papel da escola frente à sociedade é Paulo Freire e seu legado pedagógico $(1987,1996,2000)$. Suas contribuições mostram que o caminho é a educação transformadora como alicerce para a formação cidadã consciente, ética e humanizadora, com vistas à construção da autonomia, que só faz sentido e acontece pelo ato de educar. Pessoas conscientes de si e de suas responsabilidades sociais são mais engajadas com a transformação social.

É neste cenário atual de violências nas escolas, que pensamos e pesquisamos maneiras de minimizá-las por meio de estratégias de prevenção. Reconhecemos a importância da sensibilização do estafe escolar e da sociedade como um todo por meio de novos projetos e estudos que precisam ser apresentados pela escola às crianças e adolescentes, bem como a toda comunidade escolar. Vale ressaltarmos, também, que estes novos comportamentos precisam de intencionalidade, comprometimento e engajamento do mesossistema família-escola, seguindo condutas éticas como forma de reduzir as violências de forma efetiva. Uma das formas que se destaca para embasar a prevenção das violências nas escolas, por meio de projetos e programas que visam a melhoria na qualidade das interações sociais dos estudantes, é a Cultura da Paz (BANDEIRA, 2009; SALLES FILHO, 2016; MONTEIRO, 2017b).

Posto isto, a partir das considerações evidenciadas, direcionamos o presente estudo para as seguintes perguntas norteadoras: A maneira como a escola está organizada produz violências? Que espaço educativo é esse que permite que as violências se instaurem entre os estudantes, nas relações professor(a)-estudante e escola-família? Para isso, o estudo abrange a compreensão do conceito de violências no espaço escolar e, como contraponto, apresenta as concepções de Urie Bronfenbrenner (2011) e Paulo Freire (1987; 1996; 2000), sobre a escola. O primeiro destaca as influências dos ambientes para a produção de comportamentos humanos (os sistemas bioecológicos) e, o segundo, a escola como espaço de transformação social. A busca por respostas às questões norteadoras se deu a partir das reflexões e inquietações acerca da intencionalidade da função social da escola na atualidade. Trata-se, portanto, de um estudo qualitativo e teórico, em diálogo com pesquisadores 
relacionados à área da Pedagogia Social. Teve como ponto de partida pesquisas de Mestrado e estudos relacionadas à temática, oriundos de uma comunidade de prática de pesquisa (CPP) junto ao Programa de Pós-Graduação em Educação da Universidade Federal do Paraná. As pesquisas utilizadas foram submetidas ao Comitê de Ética em Pesquisa com Seres Humanos, do setor de Ciências da Saúde, da mesma Universidade e tiveram pareceres favoráveis ${ }^{2}$. Assim, o objetivo geral do estudo é ressignificar a escola como microssistema de convivência e transformação social, visto que a mesma tem sido considerada como espaço de expressão e manifestação das violências.

Ademais, reforça-se a importância e necessidade de reflexão acerca da violência escolar e suas manifestações, bem como as concepções de desenvolvimento e escola transformadora que a Teoria Bioecológica (2011) e a Pedagogia da Autonomia (1996) enfatizam ao defenderem a educação como processo de transformação e de desenvolvimento humano, no sentido da ética e da formação de valores sociais, que auxiliem na mudança de comportamento e de organização dos ambientes, visando a prevenção do fenômeno das violências nas escolas.

\section{A escola como locus das violências}

O fenômeno da violência escolar tem ganhado notoriedade e visibilidade social.

Rocha (2010) mapeou 120 (cento e vinte) estudos, entre teses, dissertações e publicações nacionais sobre violências e escola. Embora sempre tenha existido, há uma multiplicidade de formas e fatores associados ao fenômeno, que o tornam complexo. A incidência, assim como o envolvimento de crianças e adolescentes em uma cultura de violência tem crescido cada vez mais. Este processo favorece a banalização e naturalização das diferentes formas de manifestação das violências na sociedade (MONTEIRO, 2017b).

As violências têm se tornado um problema global e, por causa disso, veem provocando nos pesquisadores e na comunidade em geral, perplexidade e preocupação em relação à forma como a violência escolar vem se disseminando entre os estudantes, em especial crianças e adolescentes. O predomínio do individualismo e da impessoalidade contribui para que as nuances das violências se tornem marcas do cotidiano e não causem mais espanto (MONTEIRO, 2017b). De acordo com a Organização Mundial da Saúde (OMS, 2002), a violência, de um modo geral, pode ser definida como "uso intencional de força física ou de poder dirigida contra si próprio ou contra outra pessoa ou grupo que pode resultar em morte, maus-tratos, danos psicológicos, privação ou déficit de 
desenvolvimento". Nesse sentido, o avanço da problemática da violência no âmbito mundial ressalta que ela não se atém apenas às camadas sociais ou econômicas mais baixas. A generalização do fenômeno faz com que a sociedade, de modo geral, esteja suscetível à sua participação e às consequências (MATOS et. al., 2009, p. 23).

Refletindo sobre os diversos desdobramentos em que a violência pode se manifestar, conceituá-la exige ampliar o olhar sobre as diversas formas que a mesma atinge o ser humano. Portanto, Galtung (apud SALLES FILHO, 2016, p. 2) afirma que "a violência está presente quando os seres humanos são persuadidos de tal modo que suas realizações efetivas, somáticas e mentais, ficam abaixo de suas realizações potenciais". Assim, a violência também se manifesta nas práticas sociais que limitam o ser humano, como a pobreza, miséria, condições precárias, entre outros, que são consideradas como simbólicas e/ou estruturais. Estas manifestações abrem caminhos para outras dificuldades enfrentadas na sociedade, como a marginalização do sujeito e dos valores sociais e de convivência, bem como a busca pela criminalidade como fonte de sobrevivência. Por isso, não pode se negar à influência destas condições no âmbito escolar (MONTEIRO, 2017b).

As violências que se apresentam no microssistema escola têm se tornado um dos principais motivos de queixas nas rotinas escolares. Consideradas como um problema de saúde pública, Abramovay, Lima e Varella (2003) referem-se a três dimensões organizacionais que a violência escolar pode demonstrar: o desgaste do ambiente escolar, trazendo estruturas inadequadas e deficientes; a manifestação de gangues, tráfico de drogas e exclusão social dentro da escola e o relacionamento interpessoal interno das instituições escolares. Neste sentido, a escola tem perdido sua representação enquanto local de aprendizagem e de socialização e, portanto, a palavra locus, originada do latim, faz sentido no que diz respeito à posição da escola em relação à produção/reprodução/oportunidade das violências em seu espaço. Além disso, a escola tem ignorado as diferenças sócio culturais, dando privilégio aos valores das classes dominantes, produzindo uma violência simbólica às culturas populares (STIVAL; FORTUNATO, 2008), mesmo no âmbito das escolas públicas. As violências que envolvem crianças e adolescentes não são consideradas manifestações recentes, mas veem imbricadas pelas raízes culturais e históricas da sociedade e, mesmo assim, não podem ser admitidas como condição natural humana. É necessário diferenciar agressividade (reação do ser vivo como forma de sobrevivência) de violência.

O relato de estudantes sobre as violências que vivenciam no contexto escolar é diário. Muitos afirmam passar por humilhações, exclusões sociais, violência física e verbal. 
As agressões e transgressões ficam mais visíveis dentro das escolas, onde todos são atores vulneráveis e vítimas em potencial (SCHILLING, 2008). É nesse cenário que o bullying, por exemplo, ganha destaque como um fenômeno da violência, entre pares, que ocorre na escola, podendo ser considerado frequente e universal, mas visto como natural e normal entre os estudantes. Dar visibilidade às violências é a primeira forma de enfrentá-las (MONTEIRO, 2017b).

A escola, como locus das violências, retrata a forma como que a instituição é organizada e que, devido à sua concepção, acaba proporcionando violências. Nesse aspecto, questionamos: o que ocorre na escola que a torna espaço de violências? Um dos pressupostos diz respeito ao despreparo de educadores(as), pedagogos(as) e demais agentes educativos que leva a outras violências (limitação de saberes, ausência de afetividade, negligência, entre outras). Outra premissa que expressa a instituição escolar enquanto geradora de violências está relacionada às drogas: elas chegarão no espaço escolar. O consumo de drogas, por tratar-se de uma prática milenar, de utilização de diversas maneiras, não há como negar que as substâncias psicoativas não estarão presentes na sociedade. E, nesse âmbito, consequentemente, elas chegarão onde as pessoas estão, ou seja, até a escola. O fato das drogas chegarem no espaço escolar é preocupante, porque os agentes educativos, normalmente, não estão preparados para trabalhar com isso e, desse modo, acabam por excluir o(a) estudante ou fecham os olhos ao problema. Na maioria das vezes, professores(as) e pedagogos(as) não possuem formação inicial e continuada para abordar a temática da prevenção do abuso de drogas. Outros fatores preocupantes envolvem a organização do tempo devido a sobrecarga de atividades, bem como a ausência de apoio da gestão, em que não se oportuniza uma atuação efetiva, completa e de qualidade (LIMA, 2017a).

Infelizmente, esse cenário de despreparo profissional e de ausência de apoio da gestão não ocorre apenas no âmbito escolar, mas, também em outros espaços de interação e promoção da educação, como na educação não-escolar, por exemplo, com a atuação dos educadores sociais e nas famílias (em alguns casos, ausência de diálogo e pressão moral). Esse quadro evidencia o despreparo das universidades para formar para os temas sociais contemporâneos.

Tanto pedagogos(as) escolares, quanto educadores(as) sociais, afirmam que é necessária, e muito importante, a discussão sobre as temáticas que culminam nas violências. Por isso não se sentem preparados(as) devido à ausência de formação pedagógica e técnica. Para modificar esse cenário, é necessária uma outra organização escolar que propicie uma 
educação humanizada, onde as violências sejam impedidas de ocorrer, no campo da Pedagogia Social enquanto área de conhecimento, para acolher as problemáticas e as vulnerabilidades sociais. Um campo de desenvolvimento humano onde o(a) estudante possa ser protagonista da sua própria história, na intenção de uma real educação transformadora (LIMA, 2017a).

Com uma abordagem mais humana, há a possibilidade de preparar o sujeito para dialogar sobre o que são as drogas e como elas influenciam sua vida, como mediam a realidade, assim como o ambiente, sua história e suas relações. Faz-se necessário aumentar os fatores de proteção e diminuir os fatores de risco por meio do conhecimento, da formação pessoal e profissional (LIMA, 2017a, p. 133).

A Pedagogia Escolar e a Pedagogia Social, juntas, podem oferecer às pessoas inúmeras possibilidades de desenvolvimento humano, de diálogo e superação de riscos sociais. Para isso, Pedagogos(as) e educadores(as) precisam de preparo para lidar com as questões sociais. O fato de não estarem seguros para dialogarem sobre inúmeras formas de problemáticas que acometem as crianças e adolescentes, já torna o espaço educativo, seja ele escolar ou não, como uma forma de expressão das violências.

Justamente pela escola se apresentar como um espaço de manifestação de violências, devido a fatores como, currículo inapropriado para a realidade dos(as) estudantes, a desmotivação que gera o abandono e a evasão escolar, por exemplo, acabam por promover que as crianças e adolescentes cometam delitos e direcionem os(as) adolescentes para a socioeducação. Há uma reação em cadeia, têm sua vulnerabilidade aumentada e faz com que o desenvolvimento humano fique prejudicado. Pereira (2018) destaca que grande parte dos(as) adolescentes que cometem ato infracional estavam fora da escola. O abandono e evasão escolar se dão por diversas formas, tais como discriminação, reprovação, conflito com educadores, violação de direitos e desmotivação aos estudos. Não sentem a escola como seu espaço de pertencimento.

É comum atribuir-se (em especial as mídias) à instituição escolar uma parcela de responsabilização pelo(a) adolescente cometer um ato infracional e ir para socioeducação. O despreparo dos profissionais da educação (novamente reforçando a ausência de formação) em atuar com a diversidade de alunos, pelo preconceito, discriminação, falta de estímulo, bem como a utilização de rótulos estigmatizantes como "aluno problema", “agressivo" ou "problemático" (PEREIRA, 2018; FONSECA, 2013). 
Além do contexto da socioeducação, o ensino que é oferecido aos(às) adolescentes nesses espaços também são descritos como violências, porque no ambiente privativo de liberdade, a oferta é de Educação de Jovens e Adultos (EJA), que não retrata o perfil de adolescentes que lá se encontram. O modelo deveria ser apropriado a essa clientela, originária de realidades diversas, mas que, em comum, têm o descaso das políticas públicas e alta vulnerabilidade. Fonseca (2013, p.13) destaca que modalidade de ensino EJA não auxilia no desenvolvimento dos (das) adolescentes, uma vez que "predominam práticas pouco efetivas em termos da formação humana condizente à transformação da realidade concreta”. Desse modo, se questiona como desenvolver a autonomia? Será que esse modo de educação social oferece aos (às) adolescentes perspectivas de vida, de sonhos e projetos de vida? Questões como essas culminam no entendimento que a violência está naquilo que não se sabe trabalhar, no que os gestores escolares podem, possivelmente, fechar os olhos e negligenciar, violar direitos (PEREIRA, 2018).

Desse modo, não se trata apenas de violência concreta, vai muito além. É dialogar sobre a violência estrutural, a violência subjetiva, simbólica, que envolvem o currículo oculto (o que está por detrás e não pode ser revelado), os espaços não adequados, educadores (as) que não sabem lidar com as realidades, embora afetuosos (as). O núcleo familiar, por sua vez, não possui diálogo com a escola e, assim, podem ocorrer confrontos, uma outra forma de violência à escola. Como possibilidade de refletir sobre como romper com esse cenário violento que envolve a escola, a seguir propomos um diálogo sobre a influência do ambiente para a promoção de uma educação transformadora, com base nos estudos de Bronfenbrenner (2011) e Freire (1987, 1996, 2000).

\section{Bronfenbrenner e Paulo Freire: a escola como ambiente de convívio e transformação}

A interação entre ambiente e pessoas acontece desde o dia do nascimento do ser humano. As primeiras formas de interação ocorrem no seio familiar e, conforme os indivíduos crescem, o convívio social aumenta, ampliando as redes de relações sociais (sistema bioecológico). Partindo dessa constatação, podemos inferir que, a partir do momento que ocorrem interações entre pessoas e seus ambientes de contato, novas contribuições ao comportamento humano surgirão e, consequentemente, influências em seu desenvolvimento. A este processo dá-se o nome de transição ecológica e, dele decorrem, valores, crenças, ideias e hábitos. Portanto, são nos microssistemas de interação 
social, como a família e a escola, que as crianças e adolescentes vivenciarão suas experiências com outras pessoas e ambientes que farão parte de seu desenvolvimento. Afirmamos, então, que família e escola são essenciais para o desenvolvimento humano (BRONFENBRENNER, 2011; DINIZ; KOLLER, 2010). Posto isto, reafirmamos a importância de um ambiente familiar e escolar equilibrados para o convívio social. Entretanto, tanto a família como a escola têm se mostrado fortemente propícios para as manifestações de violências a partir de interações sociais desiguais.

O afeto é um dos elementos essenciais para o desenvolvimento humano, relacionado por Bronfenbrenner (2011) ao conceito de processo proximal. O afeto estabelece vínculos, criando redes de relações entre pessoas, o que mostra a importância deste conceito para o desenvolvimento infantil, a partir da necessidade de afetar e se deixar afetar pelo outro e pelo ambiente. Portanto, o afeto está intrinsecamente relacionado às interações sociais e a conectividade com o outro, num processo de mudanças duradouras que se iniciam na infância e se estendem ao longo da vida. Assim, cada mudança que ocorre no comportamento humano é fruto de um complexo de interações, que se realiza por meio de ações que se desenvolvem em dimensões cada vez mais complexas, incluindo pessoas, objetos e ambientes. Assim, as violências afetam o ser humano, quebram este ciclo de interação e afetividade entre pessoas, objetos e ambientes. Bronfenbrenner (2011) afirma que as mudanças que acontecem a partir da interação entre sujeitos e ambientes não ocorrem de forma fragmentada, mas que estão em constante evolução a transformação.

\footnotetext{
$\mathrm{Na}$ abordagem Bioecológica do Desenvolvimento Humano proposta por Bronfenbrenner (2011) há um posicionamento relativamente às restantes teorias da Psicologia do Desenvolvimento, as quais tendem a encarar a pessoa ou o ambiente como os únicos produtos do desenvolvimento. Pelo contrário, Bronfenbrenner considera o desenvolvimento como um processo recíproco, resultante da interação dos vários sistemas que o compõem. Assim, a transição entre cada um desses ambientes e a qualidade relacional nele estabelecidas influenciarão o trajeto desenvolvimental. (DINIZ; KOLLER, 2010, p. 67).
}

Portanto, na Bioecologia, pode-se dizer que o estabelecimento de laços afetivos promove na criança o desenvolvimento de sua capacidade física, social e simbólica. Para a promoção do desenvolvimento pleno, é preciso estabelecer relações interpessoais recíprocas. É neste envolvimento com o ambiente que ocorre o desenvolvimento. Uma criança segura estabelece relações interpessoais que interagem de tal forma que ela consegue desenvolver a segurança e a autoestima saudável. Uma criança insegura 
desenvolve relações interpessoais inadequadas e é aqui que se inicia os mecanismos da violência (DINIZ; KOLLER, 2010; BRONFENBRENNER, 2011; MONTEIRO, 2017b).

Um dos estudos desenvolvidos por Koller (2006) enfatizou a importância de ambientes favoráveis para a expressão de sentimentos positivos em indivíduos que interagem neste local. O mesmo aconteceu para aqueles que estão convivendo em ambientes desfavoráveis, onde as crianças e adolescentes que ali estão presentes, demonstram sentimentos negativos. Aqui, ressalta-se o valor de uma escola sadia e equilibrada para os estudantes. Por isso, a relevância das vivências e convivências para o modelo Bioecológico. É por meio dele que o indivíduo constrói novos conceitos do contexto vivido de forma objetiva e subjetiva. Diferentes pessoas terão diferentes experiências em um mesmo contexto dependendo da forma como conduzirão a situação vivida (DINIZ; KOLLER, 2010). Isso demonstra que o processo de construção do desenvolvimento humano é dinâmico e se dá por meio da interação.

\footnotetext{
As interações com o ambiente físico e o mundo social capacitam a criança a ampliar seus relacionamentos para além do ambiente imediato, que é a casa e as pessoas inseridas nesse contexto. Ela pode aproveitar experiências em outros contextos, como a escola, e também com outras pessoas e objetos desses contextos. (BHERING; SARKIS, 2009, p. 12).
}

Desse modo, ao considerar as crianças e adolescentes que frequentam o ambiente escolar e o processo de interação dinâmica que acontece entre pares e ambientes, as intervenções que são realizadas neste espaço favorecem ou não o desenvolvimento humano nos sujeitos. Um local que facilite ou oportunize a disseminação das violências, por meio de formas equivocadas de ação, estereótipos, discriminações, despreparo e má formação dos professores, currículos inadequados, falta de estrutura física, entre tantas outras, contribuem para a difusão das diferentes formas de violência, ao passo que as situações provocarão mudanças comportamentais nos sujeitos que ali interagem. Portanto, cuidar dos ambientes e das pessoas, mantendo-os equilibrados e harmoniosos é uma das formas de prevenir as violências no interior da escola.

Neste sentido, evidencia-se a abordagem da Cultura da Paz como base para a prevenção das violências, em especial a violência escolar. É um constructo teórico que muito se escuta nos dias atuais e, principalmente, na área educacional. É um termo que remete a valores como respeito, harmonia, altruísmo e generosidade. Portanto, construir a paz significa aderir novas atitudes: valorização de princípios de construção do coletivo, novas formas de se relacionar baseadas na empatia e no real respeito pelo outro, ver a 
diversidade como necessária, diálogo e cooperação são pontos positivos e relevantes. Assim, a Cultura da Paz se relaciona com os princípios da prevenção e da Teoria Bioecológica, uma vez que elas visam mudanças no comportamento humano, tornando-o equilibrado, harmonioso e humanitário.

\begin{abstract}
A educação para a paz não é uma solução para o que se chama violência e prevenção de guerras, mas um modo de problematizar determinados acontecimentos e remetê-los a um conjunto de práticas sociais, econômicas, políticas, culturais, históricas, educativas, comunitárias, familiares e de jogos diplomáticos internacionais (LEMOS; GALINDO, 2012, p. 135).
\end{abstract}

Ao pensar no contexto escolar como ambiente que manifesta os valores e crenças sobre o ser humano, não se pode pensar em prevenção sem antes lidar com o indivíduo e suas peculiaridades em seus ambientes de contato. Por isso, acreditamos necessários estes passos que trabalham aspectos importantes do estudante e, assim, compreender como as violências e suas formas de manifestação se dão no interior das escolas e quais procedimentos são adequados para sua prevenção.

Ao questionarmos por que a escola, que deveria ser um espaço acolhedor, é tão negligenciador? E por que permite as manifestações das violências? Há a provocação para a reflexão de que, a forma como está organizada, acaba gerando violências. Bronfenbrenner (2011), ao afirmar que o ambiente influencia e é influenciado pelos sujeitos, reforça o papel da organização dos espaços escolares como possível mobilizador de violências ou de sua prevenção. Ao dedicar-se exclusivamente aos seres humanos, a educação reforça (ou deveria salientar) a transformação do sujeito e de seu ambiente, da sua evolução na sociedade. Para isso, essa educação precisa ser capaz de provocar reflexões e práticas de liberdade. Assim como Freire (1987), Bronfenbrenner (2011) reforça que a educação envolve-se na realidade social, tornando-a um papel de mediação ativa e libertadora, tornando os humanos mais humanos. O ambiente educativo não é apenas para envolver o processo do conhecimento cognitivo, mas, também, a realização da transformação social.

Nesse sentido, a educação é retratada como norteadora, provocadora de ruptura de pensamentos e comportamentos, a fim de fortalecer o sujeito a enfrentar o sistema que atualmente vive, daquele que violenta, discrimina, abusa e escraviza, dentro de um ambiente/contexto que deixa de ser livre e passa a ser opressor, de negação aos direitos humanos fundamentais. Portanto, é nessa via que, a educação, como prática social, pode auxiliar na construção das relações sociais, na superação e/ ou transformação das 
problemáticas advindas dos conflitos familiares, escolares, comunitários e sociais (FREIRE, 1987, 2000).

A aproximação entre educador e educando reforça o diálogo, a relação social, a criação e o fortalecimento de vínculos, bem como o respeito à diversidade, à reflexão da prática e das vivências que provocam o protagonismo no espaço escolar. Esse exercício requer profunda compreensão do contexto, da história e das realidades dos sujeitos, tanto a que se vive, quanto a que se busca transformar. $\mathrm{O}(\mathrm{A})$ educador(a) necessita uma postura filosófica, de romper com as opressões e superar as imposições que o sistema os impõe no contexto escolar, uma vez que a prática da liberdade ocorre à medida que os sujeitos pensam sobre suas ações e não apenas reproduzem sem consciência (FREIRE, 1987, 1996; MONTEIRO; LIMA; ASINELLI-LUZ, 2018).

O educador precisa desenvolver uma postura filosófica, de romper com as opressões e superar as imposições que o sistema os impõe no contexto escolar, uma vez que a prática da liberdade ocorre à medida que os sujeitos pensam sobre suas ações e não apenas reproduzem sem consciência (FREIRE, 1987, p. 39).

Educar de maneira transformadora perpassa o sentido de educar de acordo com um sistema, em que precisa ser uma prática humanizadora, de estímulo à independência do(a) educando(a), da sua emancipação enquanto sujeito político, de direitos e deveres perante a sociedade. Para que ocorra essa transformação, o(a) educador(a) faz-se presença educativa, promovendo a mudança no ambiente e consequentemente, no(a) educando(a) (FREIRE, 1996).

À medida que se apresenta Paulo Freire $(1987,1996,200)$ como um mentor de ideias e ideais que reforçam e inspiram a educação voltada a um espaço de transformação social, Urie Bronfenbrenner (2011) se conecta à reflexão de modo a destacar os ambientes como contextos construtores do desenvolvimento humano. Essa afirmativa concretiza o diálogo entre gigantes: para a promoção de uma educação transformadora além do cuidado com o ser humano, é preciso cuidar de suas relações e de seus ambientes, capazes de prevenir, por meio da Cultura da Paz, as mais diversas formas de violência.

Reforçamos nesse estudo que, ao refletir sobre a escola como locus de violências, não se dê ênfase às violências escolares, mas sim, destaque-se a Teoria Bioecológica do Desenvolvimento Humano (BRONFENBRENNER, 2011), enquanto ambiente desencadeador do desenvolvimento (se buscar a mudança do comportamento, mude-se os ambientes) e evidencie-se Paulo Freire (1987, 1996, 2000), ao defender a Educação 
enquanto processo de transformação social e desenvolvimento da ética na formação dos seres humanos. Não há transformação social sem educação de qualidade.

\section{Considerações finais}

A Bioecologia do Desenvolvimento Humano enfatiza a importância dos microssistemas, em especial familia e escola para o desenvolvimento de crianças e adolescentes. A escola, em especial, discutida neste estudo, possui um papel essencial no desenvolvimento das convivências e interações entre indivíduos, bem como na formação e aprendizagem de habilidades cognitivo-acadêmicas, psicossociais, axiológicas, emocionais, que terão sua validade ecológica comprovada na vida adulta.

A Bioecologia do Desenvolvimento Humano entende que os indivíduos (todos os que se encontram no contexto do desenvolvimento, nesse caso, a escola) são determinantes para a qualidade e quantidade de relações que estabelecem nos ambientes ecológicos. A disponibilidade para a relação de qualidade é fator de proteção e prevenção das violências na escola. Portanto, destacamos a relevância da prática pedagógica na organização do ambiente escolar, de tal forma a promover relações interpessoais que auxiliem o desenvolvimento humano adequado para crianças e adolescentes. Bronfenbrenner (2011) é enfático ao afirmar que os ambientes são determinantes para mudanças de comportamento.

À luz da Teoria Bioecológica (2011), entendemos que, mesmo os agressores, no caso do bullying, por exemplo, sendo considerados agentes de violências no ambiente escolar, devem ser frutos de um ambiente permeado por manifestações de violências, reproduzindo estes padrões de comportamentos em outros contextos e ambientes (validade ecológica), que neste caso, é a escola (SCHULTZ et. al., 2012; MONTEIRO, 2017b). Evidenciamos a urgência da criação de programas de prevenção e mecanismos que privilegiam a Cultura da Paz nas escolas e em projetos que tentem minimizar ou "sanar" a violência nas escolas. É preciso envolver a comunidade escolar, porque a minimização do fenômeno envolve as pessoas, os ambientes, em um determinado tempo, os componentes pessoa, processo, contexto e tempo (PPCT), sob o ponto de vista da Bioecologia.

Além de Bronfenbrenner (2011), sobre as influências do ambiente, Freire (1987, 1996, 2000) também reforçou a reflexão sobre a escola enquanto transformação social. Trata-se de um espaço de formação humana, de busca por espaços de prevenção às violências, saudáveis, capazes de permitir o diálogo, o respeito, a diversidade, a inclusão, espaços de relações transparentes e sem opressão. 
As mais diversas formas de violências - bullying, abuso de drogas, exclusão, abandono, privação de liberdade, desrespeito, discriminação, opressão, dentre outras, ocasionam um desencontro entre o que há de realidade na escola e o que se busca pela sua transformação social. Será que a escola está descolada da sua função social? São os agentes escolares que negligenciam? E as políticas públicas? São realmente colocadas em prática e nas finalidades que foram planejadas? Há relação com a precarização do trabalho do educador, de não possuir condições para sua atuação?

A educação de qualidade é para todos. A escola é um ambiente de corresponsabilidade. Assim, é necessário reconhecer que o(a) educador(a) torna-se sujeito fundamental no processo de criação de possibilidades educativas e que, para sua efetivação, necessita de qualidade de vida profissional, envolvendo acima de tudo, a sua composição enquanto ser humano. Não formar para trabalhar com prevenção, não oferecer formação inicial e continuada e não abranger as necessidades para a escolarização, é uma forma tão cruel, quanto perversa, tanto para o(a) educador(a), quanto para o(a) educando. Oportunizar um espaço educativo transformador é, acima de tudo, ser uma oportunidade de humanização. Queremos e pretendemos sempre uma escola transformadora, nunca um espaço de expressão de violências.

1 - "O presente trabalho foi realizado com apoio da Coordenação de Aperfeiçoamento de Pessoal de Nível Superior - Brasil (CAPES) - Código de Financiamento 001".

2 - Comitê de Ética - Pareceres: no 1671640, de 10 de agosto de 2016; no 1.571.218, de 01 de junho de 2016; n 1817283 de 11 de novembro de 2016.

\section{Referências}

ABRAMOVAY, Miriam; LIMA, Fabiano; VARELLA, Santiago. Percepções dos alunos sobre as repercussões da violência nos estudos e na interação social na escola. In: (org.). Escola e violência. Brasília: UNESCO, UCB, 2003, p. 89-117.

BANDEIRA, Cláudia de Moraes. Bullying: autoestima e diferenças de gênero. Dissertação de Mestrado em Psicologia. Universidade Federal do Rio Grande do Sul, 2009.

BHERING, Eliana; SARKIS, Alessandra. Modelo bioecológico do desenvolvimento de Bronfenbrenner: implicações para as pesquisas na área da Educação Infantil. Horizontes, v. 27. n. 2, p. 7-20, 2009.

BRONFENBRENNER, Urie. Bioecologia do desenvolvimento bumano: tornando os seres humanos mais humanos. Tradução: André de Carvalho Barreto. Porto Alegre: Artmed, 2011. 
CHARLOT, Bernard. A violência na escola: como os sociólogos franceses abordam essa questão. Sociologias. Porto Alegre, v.4, n. 8, p. 432 - 443, 2002.

DINIZ, Eva; KOLLER, Silvia Helena. O afeto como processo do desenvolvimento ecológico. Educar, Curitiba. n. 36, p. 65-76, 2010.

FONSECA, Débora Cristina. Escolarização de adolescentes em privação de liberdade: análise do tema em uma amostra de periódicos. Revista Eletrônica de Educação, São Carlos, SP: UFSCar, v. 7, no. 1, p. 13-31, mai. 2013.

FREIRE, Paulo. Pedagogia da autonomia: saberes necessários à prática educativa. Paulo Freire: Paz e Terra, 1996.

FREIRE, Paulo. Pedagogia do oprimido. 23 ed. Rio de Janeiro: Paz e terra, 1987.

FREIRE, Paulo. Pedagogia da indignação: cartas pedagógicas e outros escritos. São Paulo: UNESP, 2000.

LEMOS, Flávia Cristina Silveira; GALINDO, Dolores Cristina Gomes. Violência escolar em xeque a proposta da cultura da paz no Ensino Médio. Dialogia, São Paulo, n. 16, p. 129$140,2012$.

LIMA, Tatiane Delurdes de. O educador social e o pedagogo escolar na prevenção do abuso de drogas na adolescência. 2017. 167f. Dissertação (Mestrado em Educação) - Setor de Educação, Universidade Federal do Paraná, Curitiba, 2017a.

LIMA, Tatiane Delurdes de; MONTEIRO, Michelle Popenga Geraim; ASINELLI-LUZ, Araci. A infância e a Cultura da Paz na perspectiva da Pedagogia do Oprimido. Revista eCurriculum, São Paulo, v.16, n.4, p. 1234-1251, out./dez.2018.

MATOS, Margarida; NEGREIROS, Jorge; SIMÕES, Celeste; GASPAR, Tânia. Violência, bullying e delinquência: gestão de problemas de saúde em meio escolar. Lisboa: Coisas de Ler, 2009.

MONTEIRO, Michelle Popenga Geraim. O bullying segundo a percep̧ão dos estudantes do $5^{\circ}$ ano do ensino fundamental. 2017, 148 f. Dissertação (Mestrado em Educação) - Setor de Educação, Universidade Federal do Paraná, Curitiba, 2017b.

ORGANIZAÇÃO MUNDIAL DA SAÚDE. Relatório mundial sobre violência e saúde. Genebra, 2002.

PEREIRA. Alessandra de Paula. Passado, presente e futuro: projetos de vida de adolescentes em privação de liberdade. 2018. 154 f. Dissertação (Mestrado em Educação) - Setor de Educação, Universidade Federal do Paraná, Curitiba, 2018.

ROCHA, Júlia Siqueira da. Violências nas escolas: da banalidade do mal à banalização da pedagogia. Florianópolis: Insular, 2010. 
SALLES FILHO, Nei Alberto. Pedagogia dos direitos humanos no contexto da educação para a paæ: elementos a partir dos estudos de Johan Galtung. Anais de eventos. Curitiba. Congresso de Direitos Humanos e Políticas Públicas, 2016.

SCHULTZ, Naiane Carvalho Wendt; DUQUE, Denise Franco; SILVA, Carolina Fermino da; SOUZA, Carolina Duarte de; ASSINI, Luciana Cristina; CARNEIRO, Maria da Glória de. A compreensão sistêmica do bullying. Psicologia em Estudo. Maringá. v. 17. n. 2, p. $247-$ 254, 2012.

STIVAL, Maria Cristina Elias Esper. Dominação e reprodução na escola: visão de Pierre Bourdieu. Anais de eventos. Curitiba. EDUCERE, 2008.

SCHILLING, Flávia. Educação em direitos humanos: reflexões sobre o poder, a violência e a autoridade na escola. Universitas Psychologica, v. 7, p. 685-695, 2008.

Recebido em: 15 abr. 2019 / Aprovado em: 25 jun. 2019

\section{Cite como}

MONTEIRO, Michelle Popenga Geraim; LIMA, Tatiane Delurdes de; ASINELLI-LUZ, Araci. A escola como expressão da violência ou locus da cultura da paz? Dialogia, São Paulo, n. 32, p. 65-80, maio/ago. 2019. Disponível em: https://doi.org/10.5585/Dialogia.n32.13630. 